\title{
Maxillofacial Radiology 173
}

\author{
SADJ July 2019, Vol. 74 No. 7 p401
}

\section{CJ Nortjé}

Below are more images of articular disorders which may affect the functioning of the TMJ. Discuss the most important radiological features discernible and what is your diagnosis?
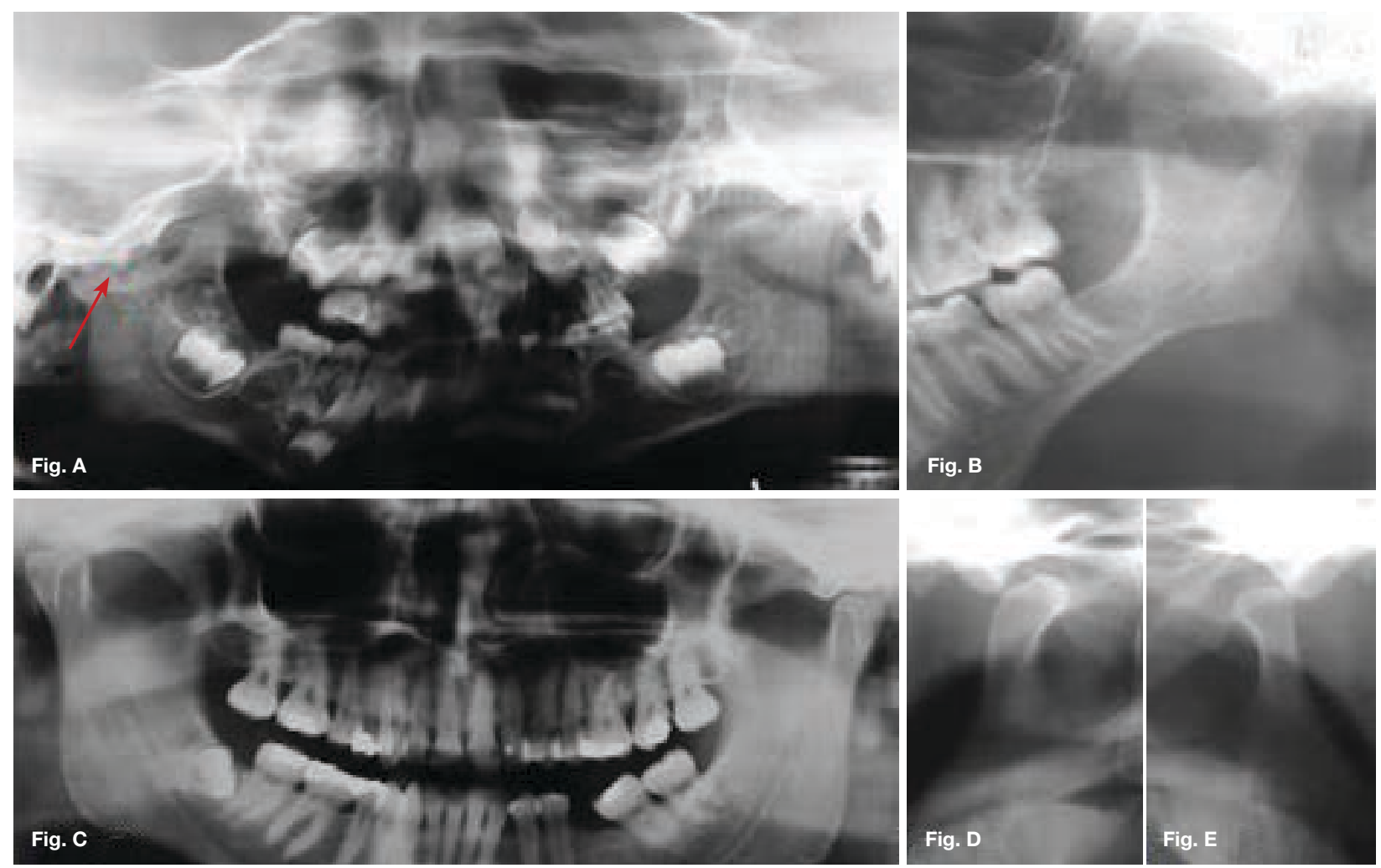

INTERPRETATION

Fig. $\mathrm{A}$ is an example of fibrous ankyloses of the right TMJ which is the fibrous union of the condyle of the man\}dible with the glenoid fossa (red arrow), resulting in immobility of the joint. Fibrous ankyloses of the TMJ, which is a variant of osseous ankyloses; the osseous components are united by fibrous tissue that has not undergone ossification. The causes are therefore the same as those for osseous ankyloses, namely inflammation resulting from localized infection; trauma to the joint and the various types of arthritis which may affect the joint. Fibrous ankylosis is a fibrous connective tissue process which results in decreased range of motion, which is why fibrous ankylosis is also known as false ankylosis. Because of the large number of possible causes, there is no clear demographic features associated with fibrous ankylosis. Fig. $\mathrm{B}$ is an example of hypoplasia of the condyle which refers to a smaller condyle than normal condyle resulting from lack of full development, as opposed to loss of condylar mass resulting from an acquired disease. Hypoplasia is often a coincidental finding on radiographs made for unrelated reasons; thus its prevalence or distribution in the population is not known.

Christoffel J Nortjé: $B C h D, P h D, A B O M R, D S c$. Faculty of Dentistry, University of the Western Cape.

ORCID Number: 0000-0002-9717-5514

Email: cnortje@uwc.ac.za

It does not appear as a common finding. The patient may have no signs of or symptoms. Deviation of the mandibular midline to the affected side ay be noted in unilateral cases, or retrognathia may be present. Fig. C Bifid mandibular condyle is a rare condition more frequently unilateral and typically discovered incidentally on imaging. The nature of this developmental condition is unknown but it may be attributed to the failure of resorption of fibrous or vascular tissue during the embryonic period leading to maldevelopment of the mandibular condyle. Figs. D\&E are examples of bilateral condyle dislocation when the mandibular condyle is displaced from the glenoid fossa usually anterior to the articular eminence. The patient is not able to return the position of the condyle to the glenoid fossa by normal masticatory muscle action. Dislocation of the TMJ may result from a variety of causes, ranging from a yawn to a blow to the jaws, especially while the mouth is open. The dislocation may be unilateral or bilateral. Extensive dental procedures, such as a third molar extraction, have also been implicated. Condylar dislocation may be more likely in individuals with shallow anterior articular eminences and those patients with lax capsules and ligaments.

\section{Reference}

1. Farman AG, Nortjé CJ \& Wood R E: Oral and Maxillofacial Imaging, $1^{\text {st }}$ Ed, Mosby. St. Louis, Missouri 1993: p350-359. 